\title{
DESEMPENHO DE CULTIVARES DE GIRASSOL EM TRÊS ÉPOCAS DE SEMEADURA NO PLANALTO NORTE CATARINENSE
}

\section{PERFORMANCE OF SUNFLOWER CULTIVARS IN THREE PLANTING DATES IN NORTH PLATEAU OF SANTA CATARINA STATE}

\author{
Alvadi Antonio BALBINOT JR. ${ }^{1}$ \\ Rogério Luiz BACKES ${ }^{1}$ \\ Adriano Martinho de SOUZA ${ }^{2}$
}

\begin{abstract}
RESUMO
Nos últimos anos houve estímulo ao cultivo do girassol no Estado de Santa Catarina, Brasil, com intuito de produção de biodiesel. No entanto, há carência em informações acerca de cultivares e épocas de semeadura adequadas às diferentes condições edafoclimáticas do Estado. O objetivo desta pesquisa foi avaliar o desempenho de dez cultivares de girassol, semeadas em três épocas na região do Planalto Norte Catarinense. As cultivares testadas foram: Aguará 3, Aguará 4, Catissol, Charrua, Dow MG2, Dow M734, Embrapa 122, Helio 358, Helio 360 e IAC larama, semeadas em 20/07/07, 25/09/07 e 18/10/07. O delineamento experimental utilizado foi o de blocos casualizados, com quatro repetições. Houve variação entre cultivares quanto ao ciclo de desenvolvimento, produtividade de grãos e outras características agronômicas. Cinco cultivares produziram mais de $2.500 \mathrm{~kg} \mathrm{ha}^{-1}$ de grãos. As maiores produtividades médias de grãos foram observadas na semeadura de julho.

Palavras-chave: Helianthus annus; produtividade de grãos; características agronômicas.
\end{abstract}

\begin{abstract}
The sunflower planting was stimulated in last years in Santa Catarina State, Brazil, with the aim to produce biodiesel. However, there is lack of information about the adequate cultivars and planting dates to different soil and climatic conditions of this State. The objective of this research was to evaluate the performance of ten sunflower cultivars, cultivated in three planting dates, under the soil and climatic conditions of North Plateau of Santa Catarina State. The cultivars tested were: Aguará 3, Aguará 4, Catissol, Charrua, Dow MG2, Dow M734, Embrapa 122, Helio 358, Helio 360 and IAC larama. These cultivars were planted in 20/07/07, 25/09/07 and 18/10/07. The treatments were arranged in a randomized block design, with four replications. There were variations in development cycle, grain yield and other agronomic traits among cultivars. Five cultivars produced more than $2,500 \mathrm{~kg} \mathrm{ha}^{-1}$ of grains. July planting date showed the highest average grain yield.
\end{abstract}

Key-words: Helianthus annus; grain yield; agronomic traits.

\footnotetext{
${ }^{1}$ Eng. Agr., Dr., Pesquisador da Empresa de Pesquisa Agropecuária e Extensão Rural de Santa Catarina (EPAGRI), Estação Experimental de Canoinhas. BR 280, km 219,5, C.P. 216, Canoinhas, SC - Brasil, CEP: 89.460-000. E-mail: balbinot@epagri.sc.gov.br (autor para correspondência); backes@epagri.sc.gov.br.

${ }^{2}$ Eng. Agr., MSc., Pesquisador da Empresa de Pesquisa Agropecuária e Extensão Rural de Santa Catarina, Estação Experimental de Canoinhas. Canoinhas, SC - Brasil. E-mail: adriano@epagri.sc.gov.br.
} 


\section{INTRODUÇÃO}

No período de 1999 a 2004, a cultura do girassol ocupou área estimada média de $91 \mathrm{mil}$ ha por ano no território brasileiro (Lazzarotto et al., 2005), área bastante restrita quando comparada às da soja e do milho. A média de produtividade de grãos neste período foi de, aproximadamente, $1.450 \mathrm{~kg} \mathrm{ha}^{-1}$. Até 2005 , os grãos de girassol eram destinados basicamente à alimentação de pássaros, produção de óleo comestível e ração para animais. Em 2005, a idéia de produzir biodiesel a partir de óleo de girassol ganhou força, o que estimulou vários agricultores a investirem na cultura (Backes et al., 2008). O teor de óleo nos grãos de girassol varia de 40 a $54 \%$, dependendo da cultivar e do ambiente de cultivo (Rossi, 1998) e, segundo Mandarino (2005), a média situa-se ao redor de $47 \%$.

Em 2006 e, sobretudo a partir de 2007, houve fomento ao cultivo do girassol em várias regiões do Brasil. Em Santa Catarina estima-se que a cultura tenha ocupado 5.200 ha no cultivo de safrinha no ano de 2007 (Backes et al., 2008). Ainda nesse ano, considerável área foi semeada com a cultura no período de safra (julho a outubro). No entanto, é certo que em muitas regiões de Santa Catarina o fomento ao cultivo do girassol vem sendo realizado sem conhecimento técnico adequado, principalmente os relacionados à viabilidade econômica da cultura. Assim, a expansão da cultura tem sido resultado de características intrínsecas da espécie, como tolerância à seca, ao frio nas fases iniciais de desenvolvimento vegetativo e ao calor, quando comparada a outras culturas anuais, como o milho e a soja (Leite, 2005).

$\mathrm{Na}$ região do Planalto Norte Catarinense, o cultivo do girassol pode ocorrer sob três estratégias: no final do inverno, com intuito de semear outras culturas estivais em seqüência (caso do milho, soja ou feijão), maximizando o uso econômico das áreas e das máquinas; no período de primavera (setembro a novembro), substituindo o cultivo de milho, soja, feijão e fumo; e na safrinha, nos meses de janeiro e fevereiro, após a colheita das espécies de verão. Em pesquisas conduzidas no Planalto Norte Catarinense, verificou-se que a semeadura do girassol em fevereiro pode proporcionar alta incidência e severidade da doença Podridão Parda do Capítulo, causada pelo fungo Sclerotinia sclerotiorum, reduzindo assim a produtividade de grãos e comprometendo o uso posterior da área com as culturas de soja, feijão e fumo (Backes et al., 2008). Além disso, nesta região, as culturas de milho, feijão e fumo não são colhidas antes do final de janeiro, o que aumenta o risco da exploração de girassol na safrinha.

Neste sentido, há necessidade de avaliar o desempenho do girassol em semeaduras no final do inverno e na primavera, com o intuito de gerar conhecimento para subsidiar o planejamento de sistemas de produção que incluam essa espécie. Adicionalmente, é necessário observar o desempenho de cultivares em diferentes épocas de semeadura, pois pode ocorrer interação entre cultivares e ambientes (Vega \& Hall, 2002; Porto et al., 2007).

O objetivo desta pesquisa foi avaliar o desempenho agronômico de dez cultivares de girassol em três épocas de semeadura na região do Planalto Norte Catarinense.

\section{MATERIALE MÉTODOS}

Foram conduzidos três experimentos no Campo Experimental Salto do Canoinhas, município de Papanduva/SC, em área da Empresa de Pesquisa Agropecuária e Extensão Rural de Santa Catarina (Epagri)/Estação Experimental de Canoinhas. O clima da região é úmido com verões amenos, do tipo $\mathrm{Cfb}$, segundo classificação de Köppen (Ide et al., 1980). O solo do local foi identificado como Latossolo Bruno Distrófico (EMBRAPA, 1999). As coordenadas geoprocessadas do local de realização dos experimentos são longitude 50'16'37' oeste, latitude $26^{\circ} 22^{\prime} 15^{\prime \prime}$ sul e altitude de $800 \mathrm{~m}$.

As cultivares de girassol avaliadas foram Aguará 3, Aguará 4, Catissol, Charrua, Dow MG2, Dow M734, Embrapa 122, Helio 358, Helio 360 e IAC larama, semeadas em três épocas: 20/07/07, 25/09/07 e 18/10/07. As cultivares Aguará 3, Aguará 4, Charrua, Dow MG2, Dow M734, Helio 358 e Helio 360 são genótipos híbridos, com elevado grau de heterose e alto potencial de produtividade de grãos, enquanto as cultivares Catissol, Embrapa 122 e IAC larama são variedades de polinização aberta. $O$ delineamento experimental utilizado foi o de blocos completos casualizados, com quatro repetições. A unidade experimental foi composta por três fileiras de cinco metros de comprimento, espaçadas em $0,8 \mathrm{~m}$. A área útil foi composta pela linha central (4 $\left.\mathrm{m}^{2}\right)$.

Os experimentos foram implantados manualmente sob sistema de plantio direto, em palha de aveia preta e ervilhaca. A adubação de base nos três experimentos foi realizada com $200 \mathrm{~kg} \mathrm{ha}^{-1}$ do fertilizante 4-20-20, da fórmula $\mathrm{N}-\mathrm{P}_{2} \mathrm{O}_{5}-\mathrm{K}_{2} \mathrm{O}$, aplicado no sulco e $8 \mathrm{~kg} \mathrm{ha}^{-1}$ de bórax, aplicados em mistura com glyphosate e óleo mineral por ocasião da dessecação da cobertura vegetal. A densidade utilizada foi de 40 mil plantas ha ${ }^{-1}$, obtida pelo raleio realizado aos 15 dias após a emergência. As adubações de base e de cobertura foram realizadas de acordo com as recomendações técnicas para a cultura (Sociedade..., 2004). Quando as plantas de girassol apresentavam, em média, cinco folhas expandidas, realizou-se uma adubação de cobertura, com $80 \mathrm{~kg} \mathrm{ha}^{-1}$ de uréia, aplicada ao lado das fileiras. Os dados de precipitação pluvial e de temperaturas máximas e mínimas do ar no período de execução dos experimentos são apresentados nas Figuras 1 e 2, respectivamente.

Nos três experimentos foram avaliadas as seguintes variáveis: diâmetro médio de capítulos (DCA), amostrando dez capítulos por parcela; quebra do caule e acamamento (QUE + ACM), considerando 


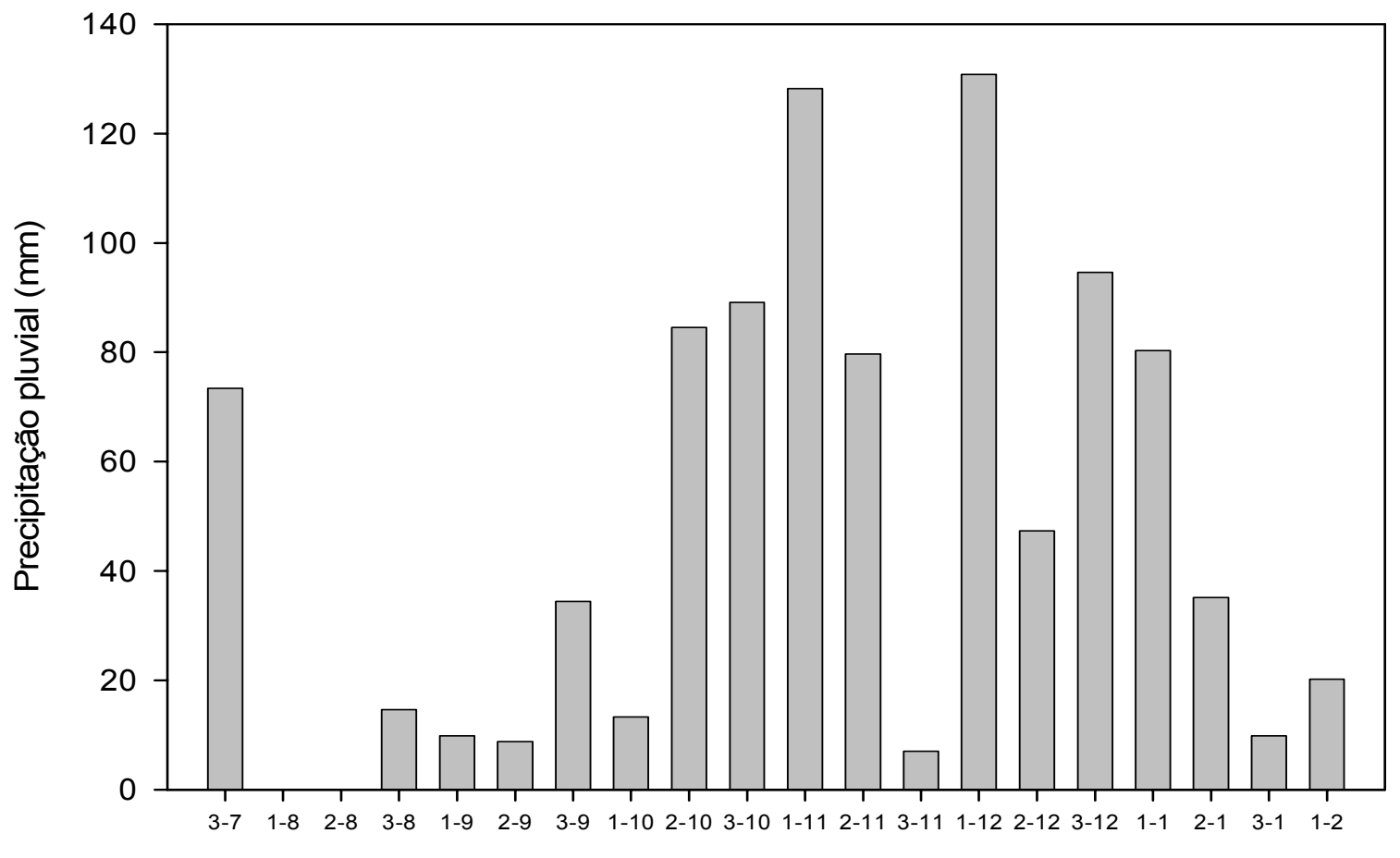

Decêndio-mês

FIGURA 1 - Precipitação pluvial por decêndio no local e período de execução dos experimentos (terceiro decêndio de julho/07 ao primeiro decêndio de fevereiro/08). Epagri, Canoinhas, 2008.

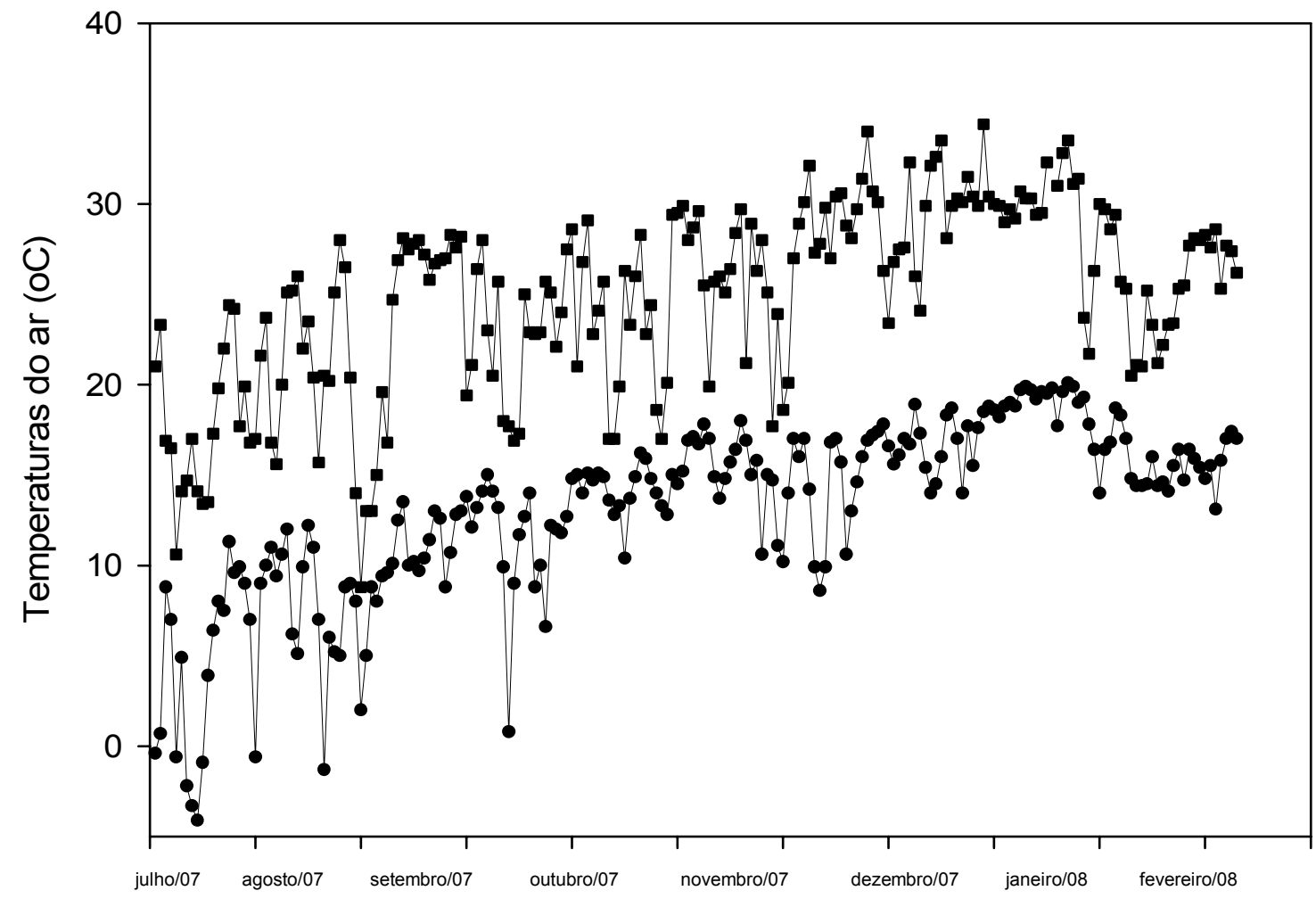

Período experimental

FIGURA 2 - Temperaturas máximas e mínimas diárias do ar no local e período de execução dos experimentos (20/07/2007 a 10/02/2008). Epagri, Canoinhas, 2008. 
BALBINOT JR., A.A. et al. Desempenho de cultivares de girassol em três épocas...

acamada a planta que apresentava ângulo entre o caule e o solo menor que $45^{\circ}$; e produtividade de grãos (PRO), corrigida para $11 \%$ de umidade. No experimento implantado em julho também foi avaliado o número de folhas emitidas até 40 dias após a semeadura (NF40); o número de dias entre a semeadura e o florescimento (NDF); e o número de dias entre a semeadura e a maturação de colheita (NDM). No experimento implantado em setembro também foi avaliado o NF40, o NDF e a massa média do grão (MAA), pesando mil grãos por parcela. A MAA também foi avaliada no experimento implantado em outubro.

Para as variáveis DCA, QUE + ACM e PRO realizou-se análise conjunta, considerando época como uma causa de variação, pois houve homogeneidade de variâncias residuais. As outras variáveis foram analisadas dentro de cada época. Os dados coletados foram submetidos à analise de variância e ao teste F. Quando constatado efeito significativo de tratamentos, as médias foram agrupadas pelo teste de Scott-Knott. Nas análises foi adotado o nível de significância de 5\%.

\section{RESULTADOS E DISCUSSÃO}

Houve diferença entre cultivares em relação ao número de folhas emitidas aos 40 dias após a semeadura (NF40) (Tabelas 1 e 2). Em semeadura de setembro, a cultivar Embrapa 122 apresentou a maior quantidade de folhas emitidas (Tabela 2), enquanto em semeadura de julho esta cultivar não diferiu de Aguará 4, Catissol e Helio 358 (Tabela 1). A velocidade de emissão de folhas é uma variável que pode afetar diretamente a interceptação de radiação solar pelo dossel da cultura e, em conseqüência, a fotossíntese bruta da comunidade de plantas de girassol (Castro \& Farias, 2005).

TABELA 1 - Características agronômicas de dez cultivares de girassol semeadas em 20 de julho de 2007 no Planalto Norte Catarinense.

\begin{tabular}{|c|c|c|c|c|}
\hline \multirow[b]{2}{*}{ Cultivares } & \multicolumn{4}{|c|}{ Características $^{(1)}$} \\
\hline & NF40 & NDF & NDM & $\mathrm{DCA}(\mathrm{cm})$ \\
\hline Embrapa 122 & $5,7 a^{(2)}$ & $85 \mathrm{~h}$ & $135 \mathrm{~d}$ & $15,6 \mathrm{c}$ \\
\hline Aguará 4 & 5,6 a & $106 \mathrm{~b}$ & $146 \mathrm{c}$ & 20,1 a \\
\hline Catissol & $5,5 \mathrm{a}$ & $88 \mathrm{~g}$ & $145 \mathrm{c}$ & $17,8 \mathrm{~b}$ \\
\hline Helio 358 & $5,4 a$ & $94 \mathrm{f}$ & $147 \mathrm{~b}$ & $17,7 \mathrm{~b}$ \\
\hline Dow M734 & $5,2 \mathrm{~b}$ & $102 d$ & 148 a & $18,4 a$ \\
\hline IAC Iarama & $5,2 \mathrm{~b}$ & $94 \mathrm{f}$ & $145 \mathrm{c}$ & 19,0 a \\
\hline Aguará 3 & $5,1 \mathrm{~b}$ & $104 \mathrm{c}$ & $146 \mathrm{c}$ & 19,0 a \\
\hline Dow MG2 & $5,0 \mathrm{~b}$ & $106 \mathrm{~b}$ & $146 \mathrm{c}$ & $19,2 \mathrm{a}$ \\
\hline Helio 360 & $5,0 \mathrm{~b}$ & $95 \mathrm{e}$ & $145 c$ & 18,6 a \\
\hline Charrua & $4,8 \mathrm{~b}$ & 108 a & 148 a & 20,6 a \\
\hline Médias & 5,2 & 98,2 & 145 & 18,6 \\
\hline C.V. (\%) & 7,2 & 0,1 & 0,6 & 6,2 \\
\hline
\end{tabular}

TABELA 2 - Características agronômicas de dez cultivares de girassol semeadas em 25 de setembro de 2007 no Planalto Norte Catarinense.

\begin{tabular}{|c|c|c|c|c|}
\hline \multirow[b]{2}{*}{ Cultivares } & \multicolumn{4}{|c|}{ Características $^{(1)}$} \\
\hline & NF40 & NDF & $\mathrm{DCA}(\mathrm{cm})$ & MAA (g) \\
\hline Embrapa 122 & $15,3 a^{(2)}$ & $68,7 \mathrm{~d}$ & 16,5 a & 64,6 a \\
\hline Catissol & $13,9 \mathrm{~b}$ & $69,0 \mathrm{~d}$ & $18,7 \mathrm{a}$ & 59,3 a \\
\hline IAC Iarama & $13,7 \mathrm{~b}$ & $69,0 \mathrm{~d}$ & 19,4 a & 66,4 a \\
\hline Aguará 3 & $13,5 b$ & $76,5 \mathrm{c}$ & 19,4 a & 58,6 a \\
\hline Aguará 4 & $13,0 \mathrm{c}$ & $79,2 b$ & 19,8 a & $51,6 \mathrm{~b}$ \\
\hline Helio 360 & $13,0 \mathrm{c}$ & $75,7 \mathrm{c}$ & 18,6 a & $48,8 \mathrm{~b}$ \\
\hline Dow M734 & $12,8 \mathrm{c}$ & $78,7 \mathrm{~b}$ & 20,0 a & 67,6 a \\
\hline Charrua & $12,7 \mathrm{c}$ & $80,0 \mathrm{~b}$ & 20,2 a & $48,6 \mathrm{~b}$ \\
\hline Dow MG2 & $12,2 \mathrm{c}$ & 83,0 a & $20,7 \mathrm{a}$ & $53,0 \mathrm{~b}$ \\
\hline Helio 358 & $12,1 \mathrm{c}$ & $77,5 \mathrm{c}$ & 19,3 a & $64,5 \mathrm{a}$ \\
\hline Médias & 13,2 & 75,7 & 19,3 & 58,3 \\
\hline C.V. (\%) & 7,0 & 2,7 & 11,2 & 9,2 \\
\hline
\end{tabular}

(1) NF40 = número de folhas emitidas aos 40 dias após a semeadura; NDF = número de dias entre a semeadura e o florescimento; NDM = número de dias entre a semeadura e a maturação de colheita; DCA = diâmetro médio dos capítulos; e MAA = massa de mil aquênios.

${ }^{(2)}$ Médias seguidas de mesma letra foram agrupadas pelo teste de Scott-Knott a $5 \%$ de probabilidade de erro. 
Constatou-se que, em semeadura de setembro, a velocidade de emissão de folhas foi superior a observada em semeadura de julho. A média de NF40 em semeadura de julho foi 5,2 e em setembro 13,2 . Isto ocorreu porque na semeadura de setembro as plantas de girassol foram submetidas a maiores temperaturas do ar em relação à semeadura de julho (Figura 2). A temperatura é o principal fator atmosférico que afeta o desenvolvimento do girassol (Castro \& Farias, 2005). A temperatura base do girassol pode variar de 4 a $8,5^{\circ} \mathrm{C}$ (Robinson et al., 1967; Villalobos \& Ritchie, 1992); ou seja, abaixo destas temperaturas não há desenvolvimento da planta. Outro fator que poderia afetar expressivamente a emissão de folhas é o déficit hídrico, o qual não foi verificado nas três épocas de semeadura (Figura 1).

É provável que Embrapa 122 apresenta rápida emissão de folhas por ser a cultivar mais precoce dentre as pesquisadas, pois tanto em semeadura de julho quanto de setembro apresentou menor número de dias entre a semeadura e o florescimento (NDF) (Tabelas 1 e 2). Em semeadura de julho, Embrapa 122 apresentou o menor número de dias entre a semeadura e a maturação de colheita (NDM) (Tabela 1), o que comprova a elevada precocidade desta cultivar. A precocidade pode ser fator importante para a inserção do girassol em sistemas de produção, permitindo outros cultivos na mesma estação de crescimento.

O diâmetro do capítulo (DCA) variou entre cultivares somente em semeadura de julho (Tabelas 1,2 e 3). Nesta época de semeadura, a cultivar Embrapa 122 apresentou o menor DCA. O DCA pode ser considerado um indicador para avaliar o desenvolvimento de plantas de girassol e a produtividade de grãos (Bruginski \& Pissaia, 2002; Castro \& Farias, 2005), embora em situações de estresse possa haver baixa produtividade de grãos, mesmo que a cultura exiba capítulos com elevado diâmetro. Adicionalmente, não houve variação significativa no DCA entre as épocas avaliadas.

TABELA 3 - Diâmetro do capítulo e massa de mil grãos em dez cultivares de girassol semeadas em 18 de outubro de 2007 no Planalto Norte Catarinense.

\begin{tabular}{lcc}
\hline Cultivares & Diâmetro do capítulo $(\mathrm{cm})$ & Massa de mil grãos $(\mathrm{g})$ \\
\hline Aguará 4 & $19,0 \mathrm{a}^{(1)}$ & $41,3 \mathrm{~d}$ \\
Charrua & $17,5 \mathrm{a}$ & $37,0 \mathrm{~d}$ \\
IAC larama & $17,4 \mathrm{a}$ & $57,4 \mathrm{~b}$ \\
Aguará 3 & $17,3 \mathrm{a}$ & $42,7 \mathrm{~d}$ \\
Dow MG2 & $17,3 \mathrm{a}$ & $55,4 \mathrm{~b}$ \\
Embrapa 122 & $16,9 \mathrm{a}$ & $64,2 \mathrm{a}$ \\
Dow M734 & $16,7 \mathrm{a}$ & $64,5 \mathrm{a}$ \\
Helio 360 & $16,6 \mathrm{a}$ & $47,1 \mathrm{c}$ \\
Helio 358 & $16,5 \mathrm{a}$ & $54,6 \mathrm{~b}$ \\
Catissol & $16,4 \mathrm{a}$ & $56,7 \mathrm{~b}$ \\
\hline Médias & 17,2 & 52,1 \\
C.V. $(\%)$ & 6,8 & 7,2 \\
\hline (1) Médias seguidas de mesma letra foram agrupadas pelo teste de Scott-Knott a 5\% de probabilidade de erro.
\end{tabular}

Em semeaduras realizadas em setembro e outubro não houve variação entre cultivares para quebra de caule + acamamento (QUE + ACM) (Tabela 4). Em semeadura de julho a maior QUE + ACM foi observada na cultivar Dow M734. A época de semeadura somente afetou esta variável na cultivar Dow M734, que apresentou maior QUE + ACM em semeadura de julho (Tabela 4). Em todas as épocas de semeadura, o erro experimental para esta variável foi elevado.

Houve variação entre cultivares para a variável massa do grão em semeadura de setembro e outubro (Tabelas 2 e 3). Em semeadura de julho esta variável não foi avaliada. Em semeadura de setembro as cultivares que apresentaram maior massa de mil grãos foram Dow M734, IAC larama, Embrapa 122, Helio 358, Catissol e Aguará 3. Em semeadura de outubro as cultivares Dow M734 e Embrapa 122 apresentaram as maiores massa do grão. Em trabalho desenvolvido por Backes et al. (2008), no Planalto Norte Catarinense, também verificou-se que a cultivar Embrapa 122 produziu grãos com elevada massa em semeadura de safrinha.
Em semeadura de julho, com exceção de Embrapa 122, todas as cultivares apresentaram produtividades de grãos superiores a $2.000 \mathrm{~kg} \mathrm{ha}^{-1}$ (Tabela 4), sendo que as cultivares mais produtivas foram Aguará 3, Aguará 4, Charrua, Dow MG2 e Dow M734, IAC larama e Helio 360. Produtividades de grãos em girassol superiores a $1.800 \mathrm{~kg} \mathrm{ha}^{-1}$ podem ser consideradas elevadas (Rossi, 1998). Em semeaduras de setembro e outubro, somente a cultivar Dow M734 apresentou produtividade superior a $2.000 \mathrm{~kg} \mathrm{ha}^{-1}$ (Tabela 4), resultado semelhante ao obtido por Carvalho \& Pissaia (2002) em experimento conduzido em Palmeira, PR, com a cultivar Dow M734. Em semeadura de setembro, a produtividade de Dow M734 não diferiu de Aguará 3. Em semeadura de outubro, a produtividade de Dow M734 não diferiu de Dow MG2. Em semeadura realizada em fevereiro, Backes et al. (2008) constataram que as cultivares Dow M734 e Dow MG2 apresentaram as maiores produtividades de grãos.

Observou-se que a semeadura de julho conferiu maiores produtividades de grãos em relação às semeaduras de setembro e outubro, com exceção da cultivar Embrapa 122, que apresentou a 
BALBINOT JR., A.A. et al. Desempenho de cultivares de girassol em três épocas...

TABELA 4 - Produtividade de grãos e quebra do caule + acamamento em dez cultivares de girassol semeadas em três épocas no Planalto Norte Catarinense.

\begin{tabular}{|c|c|c|c|}
\hline \multirow[b]{3}{*}{ Cultivares } & \multicolumn{3}{|c|}{ Produtividade de grãos $\left(\mathrm{kq} \mathrm{ha}^{-1}\right)$} \\
\hline & \multicolumn{3}{|c|}{ Épocas de semeadura } \\
\hline & 20/07/07 & $25 / 09 / 07$ & 18/10/07 \\
\hline Aguará 3 & $2.734 \mathrm{a}^{(1)} \mathrm{A}$ & 1.920 a B & $1.473 \mathrm{~b} \mathrm{C}$ \\
\hline Aguará 4 & 2.697 a $A$ & $1.641 \mathrm{~b} \mathrm{~B}$ & $1.553 \mathrm{~b} \mathrm{~B}$ \\
\hline Charrua & 2.696 a $\mathrm{A}$ & 1.464 b B & $1.267 \mathrm{~b} \mathrm{~B}$ \\
\hline Dow MG2 & 2.659 a A & 1.692 b B & 1.897 a B \\
\hline Dow M734 & 2.578 a A & 2.228 a B & 2.022 a B \\
\hline IAC larama & 2.349 a A & 1.576 b B & $1.514 \mathrm{~b} \mathrm{~B}$ \\
\hline Helio 360 & 2.316 a A & 1.551 b B & $1.634 \mathrm{~b} \mathrm{~B}$ \\
\hline Helio 358 & $2.054 \mathrm{~b} \mathrm{~A}$ & $1.172 \mathrm{~b} \mathrm{C}$ & $1.607 \mathrm{~b} \mathrm{~B}$ \\
\hline Catissol & $2.011 \mathrm{~b} \mathrm{~A}$ & 1.367 b B & 1.372 b B \\
\hline Embrapa 122 & $1.434 \mathrm{c} \mathrm{A}$ & $1.680 \mathrm{~b} \mathrm{~A}$ & $1.421 \mathrm{~b} \mathrm{~A}$ \\
\hline Médias & 2.352 & 1.629 & 1.576 \\
\hline \multirow[t]{3}{*}{ C.V. $(\%)$} & \multicolumn{3}{|c|}{14,4} \\
\hline & \multicolumn{3}{|c|}{ Quebra + acamamento (\%) ${ }^{(2)}$} \\
\hline & \multicolumn{3}{|c|}{ Épocas de semeadura } \\
\hline Cultivares & $20 / 07 / 07$ & $25 / 09 / 07$ & $18 / 10 / 07$ \\
\hline Dow M734 & $42,5 a^{(1)} A^{(1)}$ & 13,5 a $B$ & 3,0 a B \\
\hline Catissol & $23,1 \mathrm{~b} A$ & 11,9 a $A$ & 21,0 a $A$ \\
\hline Embrapa 122 & 19,3 b A & 12,9 a $A$ & 23,2 a $A$ \\
\hline IAC larama & $17,3 \mathrm{~b} \mathrm{~A}$ & 13,3 a $A$ & 13,5 a $A$ \\
\hline Helio 360 & $9,6 \subset A$ & 9,7 a $A$ & 13,5 a $A$ \\
\hline Aguará 3 & $2,9 \mathrm{c} \mathrm{A}$ & 8,0 a $A$ & 3,0 a $A$ \\
\hline Helio 358 & $1,8 \subset A$ & 12,9 a $A$ & 3,0 a $A$ \\
\hline Charrua & $1,3 \mathrm{c} \mathrm{A}$ & 9,7 a $A$ & 3,0 a $A$ \\
\hline Aguará 4 & $0,0 \subset A$ & 4,0 a $A$ & 3,0 a $A$ \\
\hline Dow MG2 & $0,0 \subset A$ & 10,6 a $A$ & 3,0 a $A$ \\
\hline Médias & 11,8 & 10,6 & 8,9 \\
\hline C.V. $(\%)$ & \multicolumn{3}{|c|}{74,0} \\
\hline
\end{tabular}

(1) Médias seguidas de mesma letra, minúsculas nas colunas e maiúsculas nas linhas, foram agrupadas pelo teste de ScottKnott a $5 \%$ de probabilidade de erro.

(2) Aplicou-se a transformação $y=\operatorname{arc~sen~}(x / 100)^{1 / 2}$ antes da análise. Os dados são apresentados na escala original.

mesma produtividade nas três épocas de semeadura (Tabela 4). Neste sentido, é possível que a cultura do girassol seja semeada em final de julho a início de agosto na região do Planalto Norte Catarinense, com intuito de semear outra cultura de interesse econômico no mês de dezembro. Outro fator a ser considerado é de que em semeaduras antecipadas o teor de óleo nos grãos de girassol é maior em relação às semeaduras tardias (novembro a dezembro) (Silva \& Freitas, 2008). Contudo, enfatiza-se que na presente pesquisa, não houve incidência de geadas intensas após a emergência de plantas de girassol, assim há necessidade de mais informações a respeito da resistência de plantas de girassol às geadas intensas, que podem ocorrer no mês de agosto na região do Planalto Norte Catarinense.

\section{CONCLUSÃO}

Cultivares de girassol apresentam boa produtividade de grãos quando cultivadas em condições edafoclimáticas do Planalto Norte Catarinense, sendo a produtividade média superior na semeadura de julho em relação às semeaduras de setembro e outubro.

\section{AGRADECIMENTOS}

Aos colaboradores e empresas pela disponibilização de sementes: Luiz Osvaldo Colasante (Instituto Agronômico do Paraná - IAPAR), Beatriz Gromick (Dow AgroSciences), Ingo Kliewer (Atlântica Sementes) e Paulo Bueno (Helianthus do Brasil).

\section{REFERÊNCIAS}

1. BACKES, R. L. et al. Desempenho de cultivares de girassol em duas épocas de plantio de safrinha no Planalto Norte Catarinense. Scientia Agraria, v. 9, n. 1, p. 41-48, 2008.

2. BRUGINSKI, D. H.; PISSAIA, A. Cobertura nitrogenada em girassol sob plantio direto na palha: II - morfologia da planta e partição de massa seca. Scientia Agraria, v. 3, n. 1-2, p. 47-53, 2002.

3. CARVALHO, D. B. de; PISSAIA, A. Cobertura nitrogenada em girassol sob plantio direto na palha: I - rendimento de grãos e seus componentes, índice de colheita e teor de óleo. Scientia Agraria, v. 3, n. 1-2, p. 41-45, 2002.

4. CASTRO, C. de; FARIAS, J. R. B. Ecofisiologia do girassol. In: LEITE, R. M. V. B. C.; BRIGHENTI, A. M.; CASTRO, C. de. Girassol no Brasil. Londrina: Embrapa Soja, 2005. p. 163-218. 
BALBINOT JR., A.A. et al. Desempenho de cultivares de girassol em três épocas...

5. EMPRESA BRASILEIRA DE PESQUISAAGROPECUÁRIA (EMBRAPA). Centro Nacional de Pesquisa de Solos. Sistema Brasileiro de Classificação de Solos. Brasília: EMBRAPA, 1999. 412 p.

6. IDE, B. Y. et al. Zoneamento agroclimático do Estado de Santa Catarina - 2a Etapa. Florianópolis: Empasc, 1980. $160 \mathrm{p}$.

7. LAZZAROTTO, J. J.; ROESSING, A. C.; MELLO, H. C. O agronegócio do girassol no mundo e no Brasil. In: LEITE, R. M. V. B. C.; BRIGHENTI, A. M.; CASTRO, C. de. Girassol no Brasil. Londrina: Embrapa Soja, 2005. p. 15-42.

8. LEITE, R. M. V. B. C. Manejo de doenças do girassol. In: LEITE, R.M.V.B.C.; BRIGHENTI, A.M.; CASTRO, C. de. Girassol no Brasil. Londrina: Embrapa Soja, 2005. p. 501-546.

9. MANDARINO, J. M. G. Óleo de girassol como alimento funcional. In: LEITE, R. M. V. B. C.; BRIGHENTI, A. M.; CASTRO, C. de. Girassol no Brasil. Londrina: Embrapa Soja, 2005. p. 43-49.

10. PORTO, W. S.; CARVALHO, C. G. P.; PINTO, R. J. B. Adaptabilidade e estabilidade como critérios para seleção de genótipos de girassol. Pesquisa Agropecuária Brasileira, v. 42, n. 4, p. 491-499, 2007.

11. ROBINSON, R. G. et al. Sunflower development at latitudes ranging from 31 to 49 degrees. Crop Science, v. 7, n. 2, p. 134-136, 1967.

12. ROSSI, R. O. Girassol. Curitiba: Tecnoagro, 1998. 333 p.

13. SILVA, P. R. F. da; FREITAS, T. F. S. de. Biodiesel: o ônus e o bônus de produzir biocombustível. Ciência Rural, v. 38, n. 3, p. 843-851, 2008.

14. SOCIEDADE BRASILEIRA DE CIÊNCIA DO SOLO. Manual de adubação e calagem para os Estados do Rio Grande do Sul e de Santa Catarina. 10. ed. Porto Alegre, RS: SBCS/Núcleo Regional Sul; Comissão de Química e Fertilidade do Solo-RS/SC, 2004. 394 p.

15. VEGA, A. J. de la; HALL, A. J. Effects of planting date, genotype, and their interactions on sunflower yield: I. determinants of oil-corrected grain yield. Crop Science, v. 42, p. 1191-1201, 2002.

16. VILLALOBOS, F. J.; RITCHIE, J. T. The effect of temperature on leaf emergence rates of sunflower genotypes. Field Crops Research, v. 29, n. 1, p. 37-46, 1992.

Recebido em 26/09/2008

Aceito em 26/11/2008 
